\title{
Relationship between sense of coherence and lifestyle in middle-aged workers in Japan
}

\author{
Ryuji Ochiai", Syunichi Daitou, Kiyoshi Aoki \\ Faculty of Human Arts and Sciences, Graduate School of University of Human Arts and Sciences, Saitama, Japan; \\ *Corresponding Author: ochoch@kbd.biglobe.ne.jp
}

Received 20 October 2011; revised 25 November 2011; accepted 6 December 2011.

\begin{abstract}
Metabolic syndrome has recently become a concern in Japan. It is commonly believed that lifestyle quality must be improved and maintained for optimum health. A cross-sectional survey of middle-aged workers was performed to examine the relationship between a sense of coherence (SOC) and health status. The study further aimed to determine the quality of life necessary to maintain physical and psychological health. An anonymous online survey was conducted with a panel of respondents registered with an Internet research service. The survey items addressed SOC and awareness of lifestyle habits, specifically lifestyle factors of self-rated health, level of satisfaction, and level of stress. Responses were obtained from 412 women and 206 men. The approximately equal high and low SOC results indicated that self-rated health and level of satisfaction were significantly higher in both sexes with a high SOC, and such participants also experienced significantly lower levels of daily stress. With regard to the association between lifestyle factors and health, women with a high SOC tended to have shorter commutes, and a higher percentage ate breakfast daily compared with women with a low SOC. Men with a high SOC worked significantly longer hours, and a higher percentage were either married or resided with family. No sex differences in SOC were observed for health behavior in daily life, and $50 \%$ of both women and men reported positive health behavior. Health behavior differed, however, according to SOC and sex. These findings suggest that health preservation in daily life of middleaged worker's women is possible through sustaining and enhancing SOC.
\end{abstract}

Keywords: Quality of Life; Sense of Coherence; Healthy Lifestyle

\section{INTRODUCTION}

Recently in Japan, concern has emerged over metabolic syndrome as a multi-risk factor for the development of atherosclerotic disease, and visceral fat obesity has also become a serious issue [1]. In 2008, the results of a government study reported that 1 of 2 male participants and 1 of 5 female participants over 40 years of age had either metabolic syndrome or were at risk for metabolic syndrome. This finding suggests that lifestyle quality must be improved and maintained for the health of Japanese men and women [2]. Simply reducing food intake, however, does not lead to a healthy, obesity-free lifestyle [3]. Those at risk must improve a variety of lifestyle habits, such as exercise, sleep, and diet, in addition to improving food intake. Improving quality of life with regard to health and maintaining it requires an overall reassessment of lifestyle habits, rather than focus on only a single aspect.

Since the enactment of the Equal Employment Opportunity Act approximately 20 years ago in Japan, remarkable progress has been made in the social advancement of women, resulting in a large number of women holding positions of responsibility. Along with this advancement, Japanese women are likely experiencing the increased social stress traditionally experienced by men, and therefore more attention should be paid to the health of women from a lifestyle disease perspective. In NIPPON DATA 80, the predictive 10-year risk factors for death due to coronary artery disease in men were blood pressure level, blood sugar level, and cholesterol level. For women, the likelihood of death from coronary artery disease was not sufficient to provide significant predictive factors [4]. Sex differences might also be evident in health habits, beliefs, and the experience of stress [5]. Thus, more effective predictive indices are needed for health maintenance in women.

An indicator of the ability to establish and maintain quality of life in relation to health is a sense of coherence (SOC), the central notion proposed in Antonovsky's salutogenesis theory [6]. SOC represents the capacity to 
maintain health and manage a variety of stressors in daily life. It comprises the three sub-concepts of 1) comprehensibility, 2) manageability, and 3) meaningfulness.

Although only a few reports exist, it is generally thought that subjects with a high SOC are able to cope more effectively with stressors by utilizing multiple general resistance resources to choose healthier lifestyle behaviors [7-9]. This effect differs among samples, however, and lifestyle behaviors reflected by the SOC remain unclear. We reported in a previous study that the SOC of university students is still being formed and does not reflect healthy lifestyle behaviors [10].

In the present study, a cross-sectional survey of middle-aged workers examined how SOC relates to health status. SOC, as an ability to maintain health, relates to lifestyle (cognition, behavior, and dietary habits), not only for deriving or being satisfied with well-being, but for health-rated quality of life. This study further aimed to determine the characteristic lifestyle factors for maintaining physical and psychological health.

\section{METHODS}

\subsection{Participants and Survey Methods}

In this study, participants responded to online survey items. All respondents were members of an Internet research service provider (Macromill, http://www. macromill.com/global/index.html), which has approximately 830,000 registered users, to align the work condition. Potential participants included men and women living in the southern Kanto region, which has the highest population of workers in Japan [11]. The questionnaire was administered twice, first as a preliminary survey and then as the main survey. On October 22, 2010, approximately 27,000 middle-aged users (40 - 59 years) of both sexes were randomly selected and recruited by email. Email messages contained information on informed consent and remuneration as well as a link to the questionnaire. Respondents were informed that upon completion of the questionnaire twice online, they would be compensated points worth a maximum of 90 yen (about 1 US Dollar) by the Internet research company. Of the 10,000 respondents, approximately 2000 full-time regular employees were selected. On October 26, 2010, 618 individuals were randomly selected from this group and invited by email to participate in the present study. Retrieved questionnaires with blanks or mistakenly entered items were excluded, and analysis was conducted on only valid responses. The study was approved by the ethics review board of the University of Human Arts and Sciences.

\subsection{Survey Content}

Survey items addressed SOC and lifestyle habits, specifically lifestyle factors of self-rated health, and level of physical and psychological health.

\subsubsection{Level of Physical and Psychological Health}

Self-rated health is a self-evaluative index of health status rated on a 5-point scale ranging from "very good" (5 points) to "poor" (1 point). Levels of overall lifestyle satisfaction, dietary satisfaction, and sleep satisfaction comprised the single index of sense of happiness. Each was rated on a 7-point scale ranging from "very satisfied" (7 points) to "very dissatisfied" (1 point). Stress was rated on a 5-point scale based on the degree of stress experienced on a daily basis ranging from "very high" (5 points) to "none" (1 point).

\subsubsection{Lifestyle Factors}

Lifestyle habits relating to health characteristics were investigated and included wake-up time, commute duration, frequency of consuming meals (breakfast, lunch, dinner, and snacks), and frequently eaten foods. The survey further examined whether respondents actively engaged in health practices, and if so, the details of those practices. Aside from wake-up time, the survey asked about the "number of nocturnal awakenings" and the "ability to wake at a predetermined time" as indicators of the ability to get up in the morning. Frequency of consuming breakfast, lunch, and dinner was rated on a 4point scale of "almost every day", "4 to 5 days a week", "around 2 to 3 days a week", and "almost never". Snacking was rated on a 5-point scale, from "five to six times per week", "three to four times per week", "one to two times per week", "one to three times a month", and "almost never". Waking ability was rated on a 4-point scale of "easy", "possible with some effort", "possible with high effort", and "cannot wake".

\subsubsection{Health Maintenance Ability}

The study used the 13-items (Japanese) version of Antonovsky's SOC questionnaire created by Yamazaki et al. [12]. The total score of the 7-point scale items was used as the SOC score. High scores indicated a high SOC. In both men and women, those with an SOC score above the median were said to have a high SOC. Those with scores below the median were designated as having a low SOC.

\subsection{Statistical Analysis}

Numeric data are represented by mean and standard deviation (SD). Student's t-test was performed on selfrated health item, each satisfaction level, and SOC total scores. A $2 \times 2$ Fisher's exact test and a $2 \times$ M MannWhitney's U test were conducted for the dichotomized SOC levels. SPSS ver. 15 (SPSS Japan Inc, Tokyo, Japan) 
was used for analysis. All tests were two-tailed, and significance levels were set at $\mathrm{p}<0.05$.

\section{RESULTS}

We analyzed the data of all 618 respondents (412 women, 206 men) from whom complete valid responses were obtained. All respondents resided in greater Tokyo or surrounding areas and were regular full-time employees. Age and SOC are shown in Table 1. No significant differences in age or SOC were detected between men and women. Survey reliability was confirmed with a Cronbach's alpha of 0.856 for SOC.

Table 2 shows the relationship between SOC and selfrated health, satisfaction, and stress. Self-rated health and level of satisfaction were significantly higher and the level of stress experienced on a daily basis was significantly lower in men and women with high SOC.

Table 3 shows lifestyle factors related to health and their relationship to SOC. Women with a high SOC tended to have significantly shorter commutes, and a higher percentage ate breakfast daily. Men with a high SOC worked significantly longer hours, and a higher percentage was either married or resided with family. "Ability to wake at a predetermined time”, one type of waking ability

Table 1. SOC scores and age.

\begin{tabular}{lcc}
\hline & $\begin{array}{c}\text { Women } \\
\text { Mean (SD) }\end{array}$ & $\begin{array}{c}\text { Men } \\
\text { Mean (SD) }\end{array}$ \\
\hline Age (in years) & $48.5(5.23)$ & $48.5(5.44)$ \\
SOC-13 & $52.4(9.82)$ & $51.7(10.16)$ \\
Comprehensibility & $20.7(4.08)$ & $20.2(4.46)$ \\
Manageability & $15.1(3.36)$ & $14.7(3.67)$ \\
Meaningfulness & $16.6(3.80)$ & $16.8(3.73)$ \\
\hline
\end{tabular}

Table 2. Self-rated health, levels of satisfaction, and stress according to high and low sense of coherence.

\begin{tabular}{|c|c|c|c|c|c|c|}
\hline & \multicolumn{2}{|c|}{ Women } & \multicolumn{4}{|c|}{ Men } \\
\hline & $\begin{array}{l}\text { High SOC } \\
\text { Mean(SD) }\end{array}$ & $\begin{array}{l}\text { Low SOC } \\
\text { Mean(SD) }\end{array}$ & & $\begin{array}{l}\text { High SOC } \\
\text { Mean(SD) }\end{array}$ & $\begin{array}{l}\text { Low SOC } \\
\text { Mean(SD) }\end{array}$ & \\
\hline $\begin{array}{l}\text { Self-rated } \\
\text { health }\end{array}$ & $\begin{array}{c}3.61 \\
(0.78)\end{array}$ & $\begin{array}{c}3.0 \\
(0.81)\end{array}$ & $* * *$ & $\begin{array}{c}3.49 \\
(0.81)\end{array}$ & $\begin{array}{l}2.96 \\
(0.78)\end{array}$ & $* * *$ \\
\hline $\begin{array}{l}\text { Overall level } \\
\text { of lifestyle } \\
\text { satisfaction }\end{array}$ & $\begin{array}{c}4.93 \\
(1.13)\end{array}$ & $\begin{array}{c}4.06 \\
(1.42)\end{array}$ & $* * *$ & $\begin{array}{c}4.89 \\
(1.24)\end{array}$ & $\begin{array}{c}3.70 \\
(1.44)\end{array}$ & $* * *$ \\
\hline $\begin{array}{l}\text { Level of } \\
\text { sleep } \\
\text { satisfaction }\end{array}$ & $\begin{array}{c}4.25 \\
(1.40)\end{array}$ & $\begin{array}{c}3.71 \\
(1.41)\end{array}$ & $* * *$ & $\begin{array}{c}4.23 \\
(1.37)\end{array}$ & $\begin{array}{c}3.44 \\
(1.44)\end{array}$ & $* * *$ \\
\hline $\begin{array}{l}\text { Level of } \\
\text { dietary } \\
\text { satisfaction }\end{array}$ & $\begin{array}{c}4.98 \\
(1.07)\end{array}$ & $\begin{array}{c}4.29 \\
(1.19)\end{array}$ & $* * *$ & $\begin{array}{c}4.93 \\
(0.90)\end{array}$ & $\begin{array}{c}4.28 \\
(1.12)\end{array}$ & $* * *$ \\
\hline $\begin{array}{l}\text { Level of } \\
\text { stress } \\
\text { in daily life }\end{array}$ & $\begin{array}{c}3.46 \\
(0.96)\end{array}$ & $\begin{array}{c}4.14 \\
(0.76)\end{array}$ & $* * *$ & $\begin{array}{c}3.50 \\
(0.86)\end{array}$ & $\begin{array}{c}4.14 \\
(0.83)\end{array}$ & $* * *$ \\
\hline
\end{tabular}

${ }^{* * *} \mathrm{p}<0.001$, between high and low SOC group using the student's t-test. was significantly easier for both men and women with high SOC. Further more, nocturnal waking was significantly lower in women with a high SOC. There were no significant differences in SOC for drinking and smoking in either sex. Women with high SOC tended to eat breakfast daily. Types of frequently eaten breakfast foods and their relationship to the SOC are shown in Table 4. Consumption of side dishes such as vegetables and eggs, in addition to the staple main dish, was significantly higher in women with a high SOC.

Table 5 shows whether health behaviors are routinely practiced, the details of such health behaviors, and their relationship to SOC. In both men and women, about 50\% of respondents reported practicing health behaviors. No differences in SOC were observed in the practice of health behaviors, but differences in the details of the health behavior were observed. A significantly higher percentage of women with a high SOC reported "light exercise, such as walking and gymnastics”, "eating nutritionally balanced meals”, and "getting adequate sleep”. A significantly higher percentage of men with low SOC reported that they "Be moderate in eating". No characteristic health behavior was observed in men with a high SOC.

\section{DISCUSSION}

This study examined how SOC relates to health status in middle-aged workers. SOC was determined by evaluating health maintenance, and health status was determined by evaluating quality of life formation. SOC includes stress-coping ability and is therefore a health indicator. Both men and women with a high SOC had significantly higher self-rated health and levels of satisfac tion, as well as low levels of stress. Thus, no sex differences were found in SOC, self-rated health, or level of satisfaction in the sample, suggesting that SOC reflects stress-coping ability. In similar research that targeted university students, no clear differences were observed in self-rated health, level of satisfaction, and SOC [10]. Therefore, SOC formed through societal living upon becoming a member of the workforce may be strongly tied to selfrated health and level of satisfaction.

The relationship of a specific health behavior to SOC for health maintenance was examined. A significantly higher percentage of health behaviors on several items were reported in respondents with a high SOC, and there were no sex differences.

Women with a high SOC tended to have shorter commutes and a higher frequency of breakfast consumption. In addition, their consumption of side dishes along with staple dishes suggests close attention to diet.

The diet of the men was not reflected by any of the items. Health behaviors are routinely practiced by about $50 \%$ of men and women. Although no sex differences 
Table 3. Health behaviors according to high and low sense of coherence.

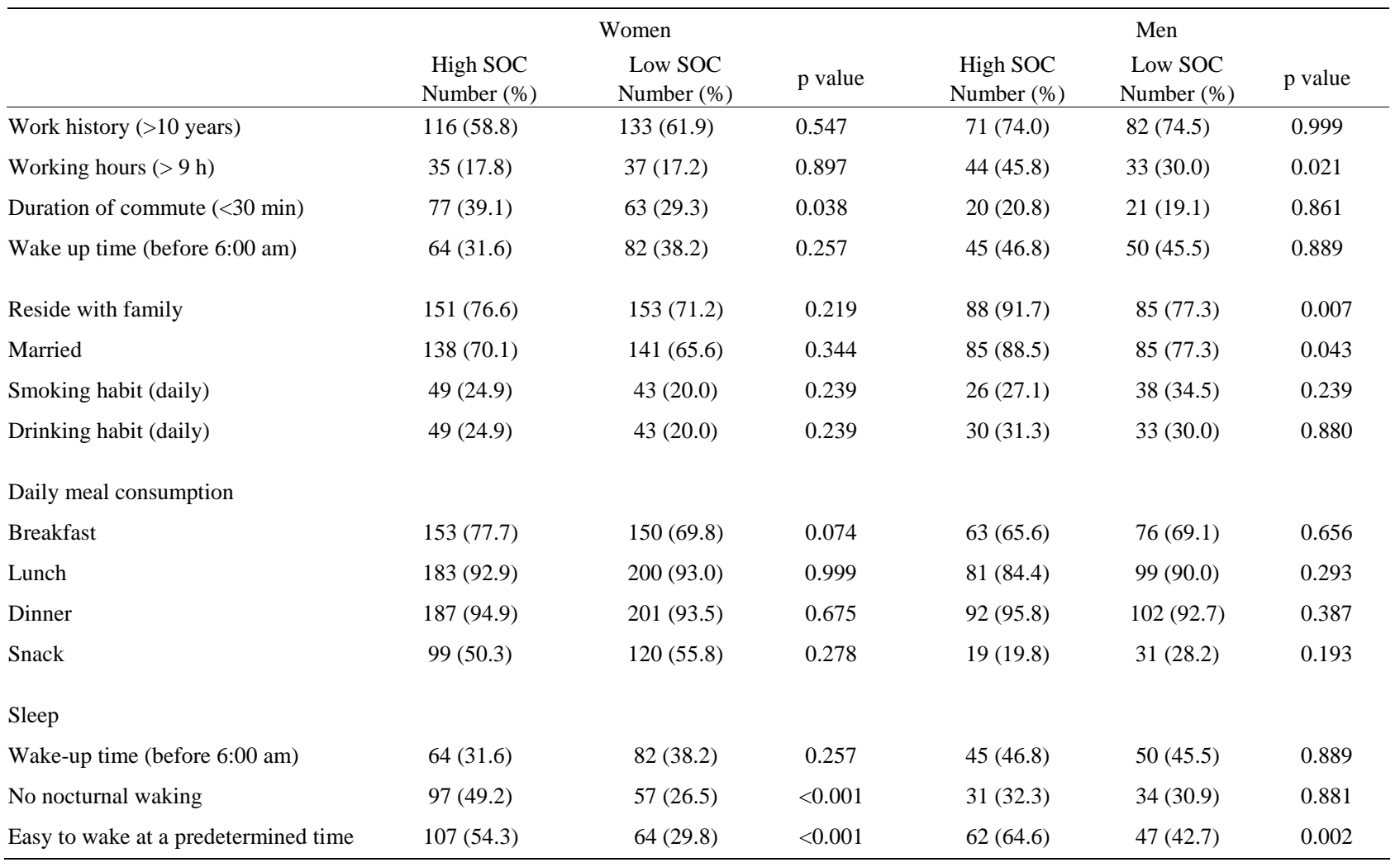

Table 4. Breakfast food choices according to high and low sense of coherence.

\begin{tabular}{|c|c|c|c|}
\hline & $\begin{array}{c}\text { High SOC } \\
\text { Number (\%) }\end{array}$ & $\begin{array}{c}\text { Low SOC } \\
\text { Number (\%) }\end{array}$ & \\
\hline Rice & $82(46.9)$ & $72(38.9)$ & \\
\hline Bread & $129(73.7)$ & $125(67.6)$ & \\
\hline Noodles & $8(4.6)$ & $8(4.3)$ & \\
\hline Cereal & $21(12.0)$ & $19(10.3)$ & \\
\hline Nutritional supplements & $5(2.9)$ & $8(4.3)$ & \\
\hline Cheese & $22(12.6)$ & $18(9.7)$ & \\
\hline Vegetable dish & $49(28.0)$ & $34(18.4)$ & * \\
\hline Egg dish & $55(31.4)$ & $34(18.4)$ & * \\
\hline Meat dish & $15(8.6)$ & 7 (3.8) & \# \\
\hline Fish dish & $14(8.0)$ & $8(4.3)$ & \\
\hline Tofu, fermented soy beans & $31(17.7)$ & $27(14.6)$ & \\
\hline Mushrooms & $8(4.6)$ & $4(2.2)$ & \\
\hline Seaweed & $12(6.9)$ & $5(2.7)$ & \# \\
\hline Yogurt & $72(41.1)$ & $72(38.9)$ & \\
\hline Gelatin & $4(2.3)$ & $2(1.1)$ & \\
\hline Cake & $7(4.0)$ & $9(4.9)$ & \\
\hline Fruit & $49(28.0)$ & $37(20.0)$ & \# \\
\hline Fruit/vegetable juice & 29 (16.6) & $26(14.1)$ & \\
\hline Soup, miso soup & $42(24.0)$ & $30(16.2)$ & \# \\
\hline Coffee, black tea & $100(57.1)$ & 96 (51.9) & \\
\hline Green tea & $32(18.3)$ & $23(12.4)$ & \\
\hline Soft drink & $12(6.9)$ & $13(7.0)$ & \\
\hline
\end{tabular}

$\#, \mathrm{p}<0.1 ; *, \mathrm{p}<0.05$; between high and low SOC group using Fisher's exact test. 
Table 5. Health practice according to high and low sense of coherence.

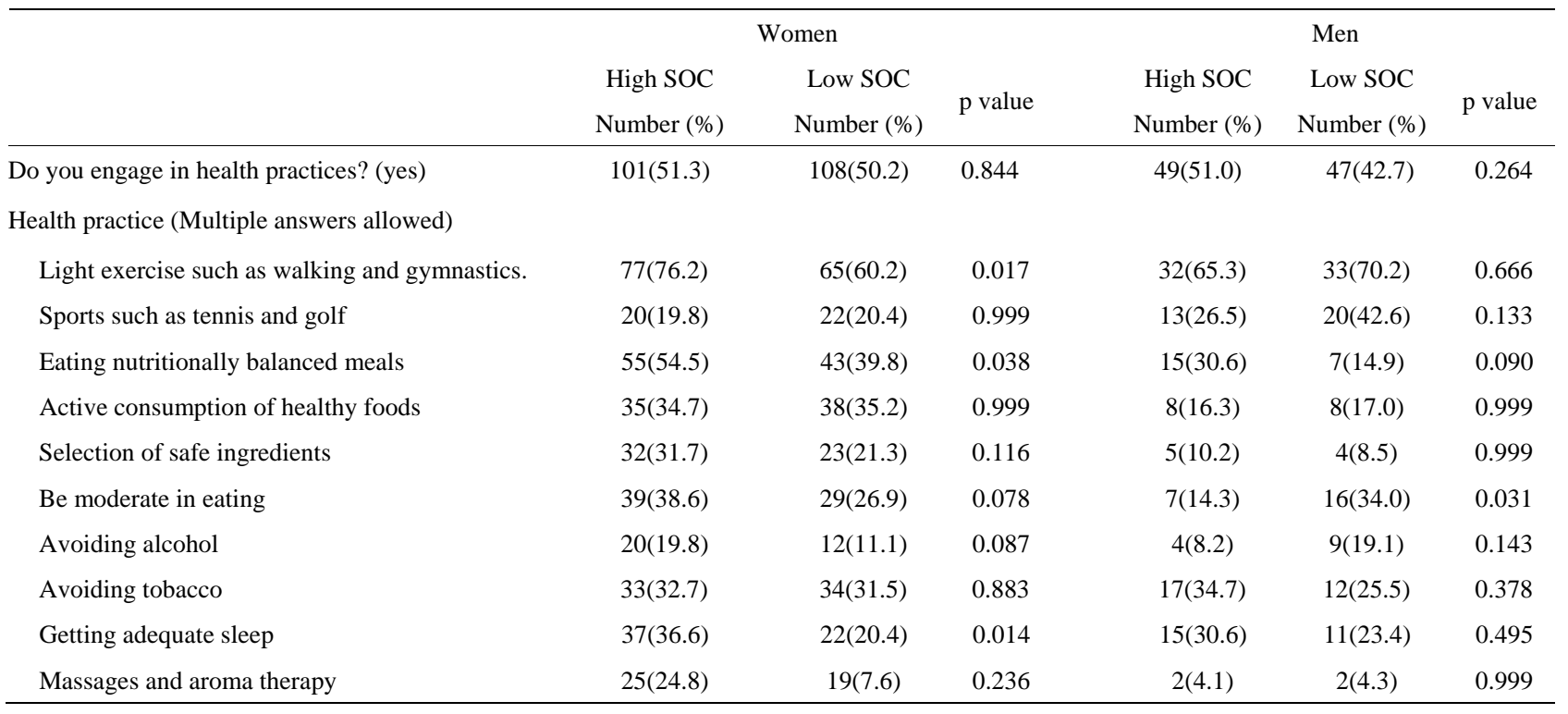

between SOC levels were observed, there were differrences in the details of health behavior. SOC was not related to health behavior in men, whereas women with a high SOC exercise, eat healthy, and sleep sufficiently. To summarize, sex differences were observed in health behaviors, and in comparison to men, the SOC of women was reflected by their specific lifestyle behaviors.

Additionally, the good sleep quality in men and women with a high SOC suggests the importance of sleep in a healthy lifestyle for both men and women. Previous research indicated that smoking frequency declines when the SOC is high $[8,13]$. This tendency was not observed in the participants of the present study. This inconsistency might be a result of the reduced smoking rates due to reinforcing non-smoking actions in the workplace as encouraged by publications of the Framework Convention on Tobacco Control (World Health Organization) [14]. Smoking rates may have decreased to below the detection threshold in this study.

These findings suggest that healthy lifestyle behaviors enhance the quality of life in women, and along with self-rated health and levels of satisfaction, are directly reflected by their SOC. In contrast, healthy lifestyle behaviors in men are not directly reflected by any factor.

There are several limitations to this study. First, causal relationships are impossible to determine because of the cross-sectional nature of the study. Second, the study sample was not all-encompassing. The sample comprised regular full-time employees and did not include temporary staff, full-time housewives, or shift workers. Moreover, the study was conducted over the Internet, leading to "digital divide" bias in the key demographics of respondents [15]. Eysenbach et al. reported that Internetbased surveys carry the issue of bias because respondents seek to participate because of their Internet capability [16]. Therefore, results obtained in this Internet-based survey may be less accurate than those of traditional selfadministered surveys. Despite these limitations, the study is meaningful in its evaluation of SOC as a predictive factor of health indices of middle-aged workers preoccupied with their careers.

\section{CONCLUSION}

The SOC of men only has evaluative potential as an indicator of stress-coping ability. Because the SOC of men was not well-reflected by health behavior or the ability to maintain health, SOC may not be an optimal indicator of health maintenance in middle-aged worker's men. In contrast, stress-coping ability, along with health behaviors related to exercise, diet, and sleep are reflected by the SOC in women, demonstrating the evaluative potential of SOC as an indicator of health maintenance in middle-aged worker's women. These findings suggest that health preservation in daily life is possible for women through SOC sustainment and enhancement.

\section{REFERENCES}

[1] Yamada, M. (2006) Metabolic syndrome concept and diagnosis. Journal of Japanese College of Angiology, 46, 417-422.

[2] Health Service Bureau. (2010) National health and nutrition survey in Japan. Minister of Health, Labor and Welfare, Tokyo.

[3] Nedeltcheva, A.V., Kilkus, J.M., Imperial, J., Schoeller, D.A. and Penev, P.D. (2010) Insufficient sleep undermines dietary efforts to reduce adiposity. Annals of Internal Medicine, 153, 435-441. 
[4] NIPPON DATA80 Research Group. (2006) Risk Assessment chart for death from cardiovascular disease based on a 19-year follow-up study of a Japanese representative population NIPPON DATA80. Circulation Journal, 70, 1249-1255. doi:10.1253/circj.70.1249

[5] Bothmer, M. and Fridlund, B. (2005) Gender differences in health habits and in motivation for a healthy lifestyle among Swedish university students. Nursing \& Health Sciences, 7, 107-118. doi:10.1111/j.1442-2018.2005.00227.x

[6] Antonovsky, A. (1993) The structure and properties of the sense of coherence scale. Social Science \& Medicine, 36, 725-733. doi:10.1016/0277-9536(93)90033-Z

[7] Eriksson, M. and Lindstrom, B. (2006) Antonovsky's sense of coherence scale and the relation with health-A systematic review. Journal of Epidemiology \& Community Health, 60, 376-381. doi:10.1136/jech.2005.041616

[8] Wainwright, N.W.J., Surtees, P.G., Welch, A.A., Luben, R.N., Khaw, K. and Bingham, S.A. (2007) Healthy lifestyle choices: Could sense of coherence aid health promotion? Journal of Epidemiology \& Community Health, 61, 871-876. doi:10.1136/jech.2006.056275

[9] Lindmark, U., Stegmayr, B., Nilsson, B., Lindahl, B. and Johansson, I. (2005) Food selection associated with sense of coherence in adults. Circulation Journal, 4, 9. doi:10.1186/1475-2891-4-9
[10] Ochiai, R., Daitou, S. and Aoki, K. (2011) The relations of the sense of coherence and lifestyles to self-rated health for college students. Journal of health Science of Mind and Body, 7, 35-40.

[11] Statistics Bureau. (2010) Labor Force Survey in Japan. http://www.stat.go.jp/english/data/roudou/154b.htm

[12] Togari, T. and Yamazaki, Y. (2005) Examination of the reliability and factor validity of 13-item five point version Sense of Coherence Scale. Japanese Journal of Health and Human Ecology, 71, 168-182. doi:10.3861/jshhe.71.168

[13] Nakamura, Y., Takao, F., Shintani, N., Shirashige, K. and Tamura, T. (2006) The effects of life style related factors on company workers' Sense of Coherence. Nursing Journal of Hiroshima International University, 4, 15-24.

[14] WHO. (2011) WHO Framework Convention on Tobacco Control. http://www.who.int/fctc/about/en/index.html

[15] Rhodes, S.D., Bowie, D.A. and Hergenrather, K.C. (2003) Collecting behavioural data using the world wide web: Considerations for researchers. Journal of Epidemiology \& Community Health, 57, 68-73. doi:10.1136/jech.57.1.68

[16] Eynsenbach, G. and Wyatt, J. (2002) Using the Internet for surveys and health research. Journal of Medical Internet Research, 4, E13. doi:10.2196/jmir.4.2.e13 